\title{
PERAN BUDAYA HUTAN LARANGAN ADAT RIAU SEBAGAI CONTOH SOLUSI PELESTARIAN EKOSISTEM DI INDONESIA
}

\author{
Christian Jefferson Setiawan, Derrick Anthony, Mutiara Zukhrufiati Asyifa, \& Wafa Aulia \\ Izzati \\ Institut Teknologi Bandung \\ Email: derrickanthonydestiny@gmail.com
}

\begin{abstract}
Abstrak
Indonesia adalah salah satu negara dengan keanekaragaman hayati terbanyak di dunia. Indonesia juga menjadi salah satu penyumbang oksigen alami terbesar di dunia. Akan tetapi, Indonesia terus kehilangan daerah-daerah hijaunya akibat ulah manusia seperti penebangan liar, kebakaran hutan, dan lainnya. Setiap tahun, Indonesia kehilangan ratusan ribu hektar kawasan hutannya akibat kepentingan pihak yang tidak bertanggung jawab. Setiap tahun, kebakaran hutan dan lahan masif selalu terjadi Indonesia, terutama di daerah Sumatra dan Kalimantan. Kebutuhan akan tindakan harus segera ditingkatkan. Disinilah salah satu peran budaya-budaya seperti budaya hutan larangan adat di Riau. Budaya hutan larangan adat di Riau selain menjaga ekosistem flora maupun fauna hutan di Riau, juga dapat menjadi harapan untuk melestarikan ekosistem alami di Riau. Penelitian ini bertujuan untuk menemukan korelasi antara budaya-budaya seperti budaya hutan larangan adat terhadap ancaman masif deforestasi di Riau melalui analisis data. Dengan menciptakan analisis data, penelitian ini diharapkan mampu memberikan data faktual berdasarkan hasil observasi dan pendapat subjektif masyarakat agar nantinya dapat mengedukasi dan memberikan kesadaran kepada masyarakat bahwa budaya hutan larangan adat tersebut bisa menjadi alasan untuk menghormati dan memahami peran budaya-budaya asli yang ada di seluruh Indonesia.
\end{abstract}

Kata kunci: Deforestasi, Budaya, Pelestarian, Hutan Larangan Adat

\begin{abstract}
Indonesia is one of the countries that have the most biodiversity in the world. Thus, Indonesia is also one of the most natural oxygen contributors in the world. However, Indonesia continuously lost its green areas because of human activity such as illegal logging, forest burning, etc. Each year, Indonesia loses about thousands of hectares of forest area because of parties' interests that are not responsible. Each year, massive forest and field fires happen in Indonesia, especially in Sumatra and Kalimantan. The needs of action must be raised as soon as possible. This is one of the cultural roles, such as the customary prohibited forest of Riau. Customary prohibited forest of Riau besides protecting the flora and fauna ecosystem in Riau, it has also become hopes to conserve the natural ecosystem in Riau. This research's aim is to find out the correlation of cultures like Customary prohibited forest with massive threat of deforestation in Riau by using data analytics. By making data analysis, this research is expected to give factual data consisting of observational results and subjective opinion in the society so that it can educate and give awareness to society that customary prohibited forest can be a reason to respect and understand countries' original cultures.
\end{abstract}

Key word: Deforestation, Culture, preservation, Customary Prohibited Forest

\section{PENDAHULUAN}

Indonesia adalah negara yang dijuluki sebagai paru-paru dunia karena Indonesia merupakan salah satu negara dengan keanekaragaman hayati terbesar di dunia. Luas hutan di Indonesia juga ketiga terbesar di dunia. Dengan hutan sebesar itu, tentu saja Indonesia secara alami merupakan salah satu penyumbang oksigen alami terbesar di dunia. Akan tetapi, menurut data dari Global Forest Watch, dari periode 2001 hingga tahun 2020, Indonesia kehilangan 10,4\% hutan primer, tepatnya sebesar 9,86 juta hektar hutan primer hilang hanya dalam rentang waktu 20012020. 
Hal tersebut terjadi karena maraknya penebangan liar, pembakaran hutan dan lahan, dan pengubahan fungsional lahan hutan oleh oknum-oknum yang hanya mementingkan kepentingan pihaknya saja. Salah satu hutan yang mengalami deforestasi terbesar adalah provinsi Riau. Menurut data yang didapat dari Badan Pusat Statistik, angka deforestasi di Riau mencapai 554368,5 hektar hutan netto dalam rentang waktu 2013 hingga tahun 2019. Angka deforestasi sebesar itu tentu saja sangat memprihatinkan untuk daerah Riau.

Akibat deforestasi yang masif, budaya hutan larangan adat di Riau semakin berarti bagi keberlangsungan ekosistem alam di Riau. Budaya hutan larangan adat di Riau adalah budaya adat Rumbio yang diturunkan untuk menjaga kelestarian hutan di kawasan kabupaten Kampar. Pentingnya penerapan sistem adat dalam pemeliharaan hutan yaitu agar dapat menjaga kelestarian hutan serta makhluk hidup di dalamnya (Firdaus, 2017) (Nurgiansah, 2020). Menurut data yang didapat dari dinas kehutanan Kampar (2010), hutan larangan adat Rumbio memiliki luas 530 ha. Jumlah tersebut tidak begitu besar dibandingkan dengan luas hutan Riau, namun, hutan larangan adat tersebut tidak dirusak sama sekali dan dibiarkan untuk berkembang semakin luas.

Penelitian lebih lanjut diperlukan untuk menemukan korelasi pertumbuhan antara budaya-budaya seperti budaya hutan larangan adat Rumbio terhadap ancaman masif pembakaran hutan dan lahan di Riau melalui analisis data. Penelitian ini diharapkan dapat memberikan edukasi tentang pentingnya pelestarian budaya-budaya asli dari Indonesia dengan menunjukkan fungsi dari budaya tersebut tidak hanya sebagai budaya, namun terdapat alasan lain dibalik hal tersebut.
Menurut KBBI, budaya adalah sudah menjadi kebiasaan yang sudah sukar diubah. Budaya juga bisa disebut sebagai bentuk dari pikiran maupun akal budi. Dari pengertian tersebut, budaya adalah sebuah kebiasaan yang terbentuk akibat adanya hasil dari pikiran maupun akal budi yang ditanamkan dalam masyarakat sehingga sulit untuk dapat diubah. Dengan demikian, adanya kebudayaan yang baik akan menciptakan kebiasaan yang baik di masyarakat. Kebiasaan yang baik di masyarakat akan menuntun pada ketentraman dan keamanan di antara masyarakat. Manusia melahirkan, menciptakan, menumbuhkan, dan mengembangkan kebudayaan (Kistanto, 2017). Oleh karena itu, dengan menciptakan budaya baru yang lebih baik dan mengembangkan kebudayaan yang baik seperti Budaya Hutan Larangan Adat Riau, maka akan timbul kesadaran di antara masyarakat.

\section{METODE PENELITIAN}

Metode yang digunakan pada penelitian ini adalah metode historis komparatif dan metode penelitian survei. Metode penelitian historis komparatif bertujuan untuk membandingkan data-data dari sumber terpercaya dengan membandingkan data antara laju pertumbuhan hutan larangan adat Rumbio terhadap data laju deforestasi di daerah Riau. Metode penelitian survei bertujuan untuk menemukan pendapat subjektif dari masyarakat terhadap pentingnya budaya secara umum dan juga budaya pelestarian alam seperti budaya larangan adat Rumbio tersebut. Data yang didapatkan kemudian akan diproses dan dianalisis menggunakan beberapa metode analisis, yaitu analisis secara grafik dan perhitungan jika diperlukan. Dengan berdasarkan hasil analisis tersebut, akan dilakukan pengambilan kesimpulan berdasarkan data tersebut melalui pendapat kelompok. 
Teknik yang digunakan dalam mengumpulkan data adalah studi Kepustakaan, dilakukan dengan mencari data dari sumber yang sah dan dapat dipercaya kebenarannya. Lalu Penyebaran kuesioner, dilakukan untuk melakukan pencuplikan terhadap masyarakat secara acak. Target responden adalah masyarakat ITB maupun Non-ITB dengan jumlah minimal responden sebanyak 50 responden.

\section{HASIL PENELITIAN DAN PEMBAHASAN Hasil Penelitian}

Penyebaran kuesioner yang kelompok kami lakukan ditujukan untuk menanyakan tentang keadaan alam di Indonesia dan budaya di Indonesia menurut sudut pandang orang lain. Kuesioner yang telah kelompok kami buat telah diisi oleh 57 responden yang merupakan mahasiswa ITB dan juga mahasiswa non-ITB. Menurut hasil kuesioner, pelestarian alam di Indonesia mendapatkan nilai 2,7 dari 5 poin $(53,68 \%)$ didapat dari rata-rata nilai yang diberikan oleh responden, penilaian terhadap budaya di Indonesia telah dihargai dengan baik mendapatkan nilai 3,08 dari 5 poin $(61,75 \%)$, penerapan sistem adat penting dalam pemeliharaan hutan lindung mendapatkan nilai 4,54 dari 5 poin $(90,87 \%)$.

\section{Pembahasan}

Hutan adalah sebuah ekosistem yang kompleks, yang menjadi rumah bagi ratusan bahkan ribuan jenis satwa dan tumbuhan, menyuplai kita dengan air bersih dan udara segar, dan menjaga iklim dan temperatur bumi tetap stabil. Lebih dari itu, hutan juga memberi penghidupan bagi masyarakat yang hidup didalam dan di sekitarnya, serta kelompok pengusaha yang memanfaatkan hasil hutan sebagai komoditas konsumsi sehari-hari. Saat fungsi hutan hilang, kerugian akan dirasakan oleh semua pihak, dari masyarakat setempat hingga masyarakat urban. Hutan Indonesia merupakan rumah bagi keanekaragaman hayati dan memainkan peran penting dalam mitigasi perubahan iklim dan ketahanan air. Hutan juga menjadi tempat tinggal bagi banyak kelompok masyarakat adat dan komunitas lokal. Namun, pada saat ini sektor kehutanan telah dipenuhi eksploitasi yang berlebihan, konflik sosial, dan korupsi. Tata kelola hutan tengah dalam kondisi kritis pada berbagai level (WWF, 2015) (Nurgiansah, 2021).

Hutan merupakan sumber daya alam yang cukup potensial dan memiliki peran strategis dalam pembangunan. Dengan peran yang cukup strategis tersebut, konsep pengelolaan hutan di Indonesia bersifat dinamis, sesuai dengan kepentingan dan kebutuhan yang ingin dicapai. Fungsi hutan dalam pelayanan jasa lingkungan diberikan oleh keberadaan hutan sebagai penyerap karbon, perlindungan plasma nutfah, keanekaragaman hayati, dan nilai-nilai estetika yang potensial bernilai ekonomi apabila dapat dikelola dengan tepat. Hutan tidak hanya berkaitan dengan ekonomi perkayuan saja, tetapi amat jauh menjangkau berbagai sistem ekonomi, sosial dan budaya yang beraneka ragam, yang juga merupakan potensi untuk mengembangkan berbagai bidang ilmu dan teknologi (Azwar et al., 2021).

Menurut Global Forest Watch (2020), dari tahun 2001 sampai 2020 Indonesia kehilangan 9,86 juta hektar hutan primer lembab, yang merupakan $36 \%$ dari total kehilangan pohon dalam periode waktu yang sama. Berikut adalah grafik analisis deforestasi di Indonesia dari tahun 20022020. 


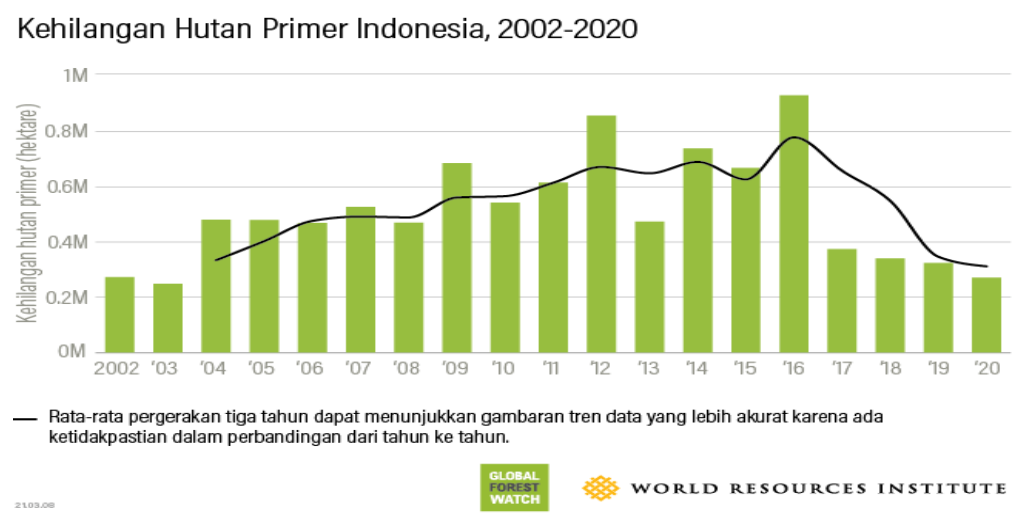

Gambar 1. Grafik histogram jumlah kehilangan hutan primer Indonesia tahun 2002-2020

Berdasarkan grafik, dapat dilihat bahwa dari tahun ke tahun, deforestasi di Indonesia menunjukkan tren peningkatan dimana tahun 2016, deforestasi di Indonesia menunjukkan angka tertinggi. Tetapi setelah tahun 2016, deforestasi di Indonesia menunjukkan penurunan secara signifikan dalam kurun waktu 5 tahun.

Hutan adat merupakan pilihan hukum masyarakat untuk mengelola hutan di dalam kawasan hutan negara. Hutan adat dikhususkan untuk diberikan kepada masyarakat hukum adat. Bagi masyarakat adat, Hutan adat menjadi kesatuan yang tidak bisa dipisahkan. Hutan menjadi bagian dari kehidupan masyarakat adat yang telah menopang kehidupan seharihari, dan juga titipan bagi generasi yang akan datang. Hutan adat menjadi salah satu kekayaan penting bagi masyarakat adat untuk menjamin kesejahteraan hidupnya (Dewi, Handayani, \& Najicha, 2020). Maka dari itu, Presiden Joko Widodo menaruh perhatian yang sangat besar terhadap semua suku bangsa yang ada di Indonesia dan tidak memiliki keraguan sedikitpun untuk mengakui keberadaanya. Penyerahan 8 SK Penetapan Hutan Adat pada 30 Desember 2016, dan 35 SK selanjutnya pada 7 Januari 2021 oleh Presiden, mempertegas ketidakraguan pemerintah untuk terus melakukan percepatan pengakuan terhadap kawasan hutan adat di seluruh Indonesia.
Sebagai negara yang majemuk dengan beragam suku bangsa dan budaya, pengakuan terhadap Masyarakat Hukum Adat (MHA) dan kawasan hutan adatnya, menjadi salah satu bukti kehadiran Pemerintah untuk melindungi hak masyarakat tradisional sekaligus mensejahterakannya dalam bingkai sistem Pemerintahan Negara Kesatuan Republik Indonesia. Komitmen Pemerintah dalam melindungi MHA dan kearifan lokalnya semakin nyata dengan diterbitkannya Peraturan Menteri Lingkungan Hidup dan Kehutanan Nomor P. 9 tahun 2021 tentang Pengelolaan Perhutanan Sosial. Di dalam aturan tersebut komitmen pemerintah diperjelas salah satunya dengan menetapkan Peta hutan Adat dan Wilayah Indikatif Hutan Adat yang ditanda tangani oleh Menteri Lingkungan Hidup dan Kehutanan seluas $\pm 1.090 .755 \mathrm{Ha}$ (Kementerian Lingkungan Hidup dan Kehutanan, 2021).

Hutan larangan adat Kenegerian Rumbio terbentang di empat desa yaitu Desa Koto Tibun Desa Padang mutung, Desa Rumbio dan Desa Pulau Sarak. Total luas hutan larangan adat Kenegerian Rumbio lebih kurang 530 ha (Purwanto, 2013). Hutan Larangan Adat Kanagarian Rumbio ini merupakan hutan lindung yang dikelolah oleh masyarakat adat Desa Rumbio yang berada dalam kesatuan adat yang dipimpin oleh ninik mamak sebagai 
para petinggi. Keberlanjutan dan kelestarian hutan larangan adat Kenegerian Rumbio dimasa yang akan datang akan sangat bergantung dari partisipasi semua pihak (pemangku adat, pemerintah, alim ulama dan masyarakat) dapat terus menjaga dan melestarikan kearifan lokal yang telah ada dan dijalankan bertahun tahun lamanya dalam pengelolaan Hutan larangan Adat Rumbio demi kesejahteraan bersama masyarakat Rumbio baik saat ini maupun di masa yang akan datang (Azwar et al., 2021).

Berdasarkan hasil kuesioner, sebagian besar responden menjawab bahwa alam di Indonesia kurang dilestarikan dengan baik. Banyak masyarakat beranggapan bahwa hutan di Indonesia masih belum terlestari dengan baik. Hal tersebut bisa terjadi dikarenakan oleh banyaknya alam yang sudah rusak akibat tren deforestasi yang tinggi. Masyarakat juga menilai bahwa budaya juga masih belum dihargai dengan baik. Hal tersebut terjadi akibat beberapa faktor. Faktor utama kurang dihargai budaya satu sama lain adalah perspektif subjektif tentang budaya yang berbeda-beda dan cenderung kurang toleransi. Banyaknya responden yang setuju diterapkannya hutan larangan Adat Rumbio menunjukkan bahwa setiap budaya dapat dijadikan sebagai contoh dalam bermasyarakat sekaligus memberikan peringatan kepada khalayak ramai untuk menjaga budayabudaya yang ada.

\section{KESIMPULAN}

Setiap budaya yang ada bisa ada akibat adanya tujuan tertentu. Tidak ada budaya yang buruk, hanya saja, budaya tersebut bukan budaya yang cocok dalam bermasyarakat. Untuk itu, setiap budaya harus dihargai dan dilestarikan. Salah satu budaya yang memiliki tujuan untuk menjaga kelestarian alam adalah hutan Larangan Adat Rumbio. Setiap tahun, deforestasi di Indonesia menunjukkan penurunan, namun tidak dapat dipungkiri bahwa deforestasi di Indonesia sewaktuwaktu akan meningkat kembali. Saat ini, ekosistem di Indonesia terus tercemar oleh banyaknya aktivitas manusia. Budaya hutan Larangan Adat Rumbio merupakan salah satu cara agar masyarakat dapat menjaga kelestarian ekosistem di Indonesia. Dengan adanya larangan adat, maka interaksi antara manusia dengan alam dapat dijaga seminimal mungkin sehingga ekosistem di dalam hutan dapat tetap terjaga hingga bertahun-tahun lamanya.

\section{DAFTAR PUSTAKA}

Aman. (2018). Apa Itu Hutan Adat? https://www.aman.or.id/apa-itu-hutan-adat. Diakses pada tanggal 15 November 2021 pukul 15.45.

Azwar et al. (2021). Strategi Keberlanjutan Pengelolaan Hutan Larangan Adat Kenegerian Rumbio Kabupaten Kampar Provinsi Riau. Universitas Islam Negeri Sultan Syarif Kasim Riau. p. 57-64

Badan Pusat Statistik. (2019). Angka Deforestasi Netto Indonesia Di Dalam dan Di Luar Kawasan Hutan Tahun 2013-2019. Badan Pusat Statistik. Diakses pada tanggal 15 November 2021 pukul 13.30.

Dewi, S. H. S., Handayani, I. G. A. K. R., \& Najicha, F. U. (2020). Kedudukan Dan Perlindungan Masyarakat Adat Dalam Mendiami Hutan Adat. Jurnal Legislatif, 79-92.

Firdaus. (2017). Peran Lembaga Adat Kenagarian Rumbio Dalam Pelestarian Hutan Larangan Adat (Studi: Hutan Larangan Adat Kenagarian Rumbio Kecamatan Kampar Kabupatan Kampar). Jurusan Ilmu Pemerintahan Fakultas Ilmu Sosial dan Politik. Universitas Riau. p.1-11. 
Global Forest Watch. (2020). Indonesia Interactive Forest Map \& Tree Cover Change Data:GFW.https://www.globalforestwatch.org/map/country/IDN/?mainMap =eyJzaG930W5hbHlzaXMiOnRydWV9\&map=eyliZW50ZXIiOnsibGF0IjotMi41Nzg0NT MwNjA10TEzOTMzLCJsbmciOjExOC4wMTUxNTU30TAwODQ50X0sInpvb20iOjQuMzc 3NDE2MjYwNTAyOTQ2NSwiY2FuQm91bmQiOmZhbHNlfQ\%3D\%3D\&mapPrompts=e yJvcGVuIjp0cnVlLCJzdGVwc0tleSI6InN1YnNjcmliZVRvQXJIYSJ9. Diakses pada tanggal 15 November 2021 pukul 13.00.

Kementerian Lingkungan Hidup dan Kehutanan. (2021). Pemerintah Terus Percepat Pengakuan Hutan Adat. http://ppid.menlhk.go.id/berita/siaran-pers/6121/pemerintah-teruspercepat-pengakuan-hutan-adat. Diakses pada tanggal 15 November 2021 pukul 15.15.

Kistanto, N.H. (2016). Tentang Konsep Kebudayaan. Fakultas Ilmu Budaya Universitas Diponegoro. P. 1-11.

Moeliono et al. (2008). Apa Kata Mereka Tentang Hutan Adat dan Hutan Desa. Working Group on Forest Land Tenure. P.13-15.

Nurgiansah, T. H. (2020). Filsafat Pendidikan. In Banyumas: CV Pena Persada.

Nurgiansah, T. H. (2021). Pendidikan Pancasila. In Solok: CV Mitra Cendekia Media.

WWF. (2015).Global Environmental Conservation Organization - WWF Indonesia. https://www.wwf.id/program/hutan. Diakses pada tanggal 15 November 2021 pukul 13.50 